\title{
Effect of coastal topography on the spatial structure of the populations of small pelagic fish
}

\author{
M. Giannoulaki ${ }^{1, *}$, A. Machias ${ }^{1}$, C. Koutsikopoulos ${ }^{2}$, J. Haralabous ${ }^{1}$, S. Somarakis ${ }^{1,2}$, \\ N. Tsimenides ${ }^{1}$ \\ ${ }^{1}$ Institute of Marine Biology of Crete, PO Box 2214, 71003 Iraklion, Crete, Greece \\ ${ }^{2}$ University of Patras, Department of Biology, 26500 Patra, Greece
}

\begin{abstract}
Acoustic data from 6 research surveys (4 in summer and 2 in winter) in the Aegean and Ionian Seas (eastern Mediterranean Sea) were analyzed to examine the effect of coastal topography on the spatial structure of populations of small pelagic fish using geostatistical techniques (omnidirectional and exhaustive variograms). The effect of topographic characteristics related to depth and the degree of land enclosure on the spatial structure of fish populations (as expressed by several parameters calculated from omnidirectional and exhaustive variograms) was studied by multiple regression analysis. The estimated autocorrelation range of omnidirectional variograms indicated that fish formed meso-scale to large-scale patches, but it was not significantly related to any of the area characteristics examined. The nugget effect was negatively correlated with mean bottom depth. Parameters related to anisotropy, calculated from the exhaustive variograms, did not show any consistent pattern related to the geographical characteristics of the area studied. Geometric descriptors of the exhaustive variograms provided a more detailed picture of the underlying spatial continuity, indicating the effect of the enclosure index (stronger in summer) and the size of the area (stronger in winter) on the spatial structure of fish populations. The organization of fish into clusters of schools was heterogeneous in closed sub-areas during both seasons and, for a given degree of enclosure, they were more homogeneous in small-sized sub-areas than in large sub-areas. These results suggest that the environmental spatial heterogeneity mainly affected the way schools were organized into aggregations rather than the maximum size of the area occupied by these aggregations.
\end{abstract}

KEY WORDS: Small pelagic fish $\cdot$ Spatial structure $\cdot$ Degree of enclosure $\cdot$ Exhaustive variograms Resale or republication not permitted without written consent of the publisher

\section{INTRODUCTION}

The production of small pelagic fish (anchovies, sardines, herrings, gilt-sardines etc.) represents an important part of the world fish landings, ranging from onethird to nearly half of the global annual totals (Freon \& Misund 1999). These species form either pure or mixed schools (Bakun \& Cury 1999) and may adjust their spatial extension to maintain constant density within schools (Petitgas et al. 2001). The organization of schools into clusters has already been described for many stocks (Freon \& Misund 1999, Petitgas et al. 2001 and references therein), and is probably related to the patchiness of the environment (Schneider 1989, Swartzman 1991). Within a cluster of schools the spa- tial distribution can be very heterogeneous. Knowledge of the spatial organization of pelagic fish stocks is essential for fisheries scientists because it may affect both stock catchability and the results of assessment surveys, as well as contribute to the understanding of fundamental ecological processes affecting the population (Freon \& Misund 1999).

Recognition of the importance of the spatial heterogeneity of fish aggregations has led to the development of sampling methodologies, statistics and models that deal specifically with this type of variation. Geostatistical techniques have been widely applied over the last few years in fisheries science to analyze patterns in fish distribution, and to optimize the design of sampling schemes and the precision of abundance 
estimates (Petitgas 1993a, Maravelias \& Haralabous 1995, Maravelias et al. 1996, Petitgas \& Lévénez 1996, Barange \& Hampton 1997, Petitgas 1997, Fletcher \& Summer 1999, Bez \& Rivoirard 2001).

Petitgas (1993a) has suggested that the structure and location of fish patches are strongly affected by 2 major agents: (1) the specific way in which the fish occupies available space; and (2) the geometry of the habitat. However, most related studies on the spatial organization of fish populations using geostatistical techniques refer to open sea areas, such as the North Sea (Petitgas 1993b, Maravelias et al. 1996), Senegalese waters (Petitgas \& Lévénez 1996), the southern Benguella upwelling region (Barange \& Hampton 1997), the Bay of Biscay (Petitgas 1997) and the south coast of western Australia (Fletcher \& Summer 1999), where the topography may have a minor effect on the spatial structure of fish populations.

In the present study, data from 6 acoustic surveys ( 4 in summer and 2 in winter) in the Aegean and Ionian Seas (eastern Mediterranean Sea) were used to examine the effect of coastal topography on the spatial structure of the overall assemblages of small pelagic fish. The surveyed areas were highly variable, consisting of differentsized open as well as semi-enclosed regions that were connected to each other by narrow passages (Stergiou et al. 1997). Data were analyzed using geostatistical techniques (omnidirectional and exhaustive variograms; Isaaks \& Srivastava 1989, Rossi et al. 1992) and multiple regression analysis was applied to examine the effect of topography on the spatial structure of the aggregations of small pelagic fish. Omnidirectional variograms were useful in describing the general characteristics of the spatial structure of fish aggregations, and exhaustive variograms provided detailed information on the internal organization of their spatial structure.

\section{MATERIALS AND METHODS}

Sampling. Acoustic data were collected during research surveys carried out along predetermined transects (Bazigos 1974, Tsimenides et al. 1992) in the North Aegean Sea (Thracian Sea, Strymonikos Gulf and Thermaikos Gulf; June 1995 and 1996), the central Aegean Sea (North and South Evoikos Gulf; July 1998, June and December 1999, December 2000) and the Ionian Sea (Corinthiakos Gulf, Patraikos Gulf, Ionian Sea; July 1998, June and December 1999, January 2001) (Table 1, Fig. 1). Biosonic Dual Beam 120 kHz V-Fin Echosounder (Model 120, $3^{\circ}+3^{\circ}$ ) acoustic equipment was used. The system was regularly calibrated using the standard sphere method (Foote 1987). A Dual Beam Processor ESP Model 281 and a Garmin GPS were used to determine longitude and latitude of the backscattering signal. The echoes were processed using ESP v3 software (Biosonics 1992). The speed of the vessel was 8 nautical miles $(\mathrm{nm}) \mathrm{h}^{-1}$. Acoustic echoes were registered continuously along transects and were integrated over $1 \mathrm{~nm}$, which served as the elementary distance sampling unit (EDSU). A pelagic trawl with a vertical opening of $10 \mathrm{~m}$ and a $10 \mathrm{~mm}$ codend was used to identify echo traces. Catch composition of 100 hauls revealed that the main species in all areas were Engraulis encrasicolus, Sardina pilchardus, and Trachurus spp., while Sardinella aurita and Scomber spp. represented less than $10 \%$ of the catches.

In this study, we focused on total small pelagic assemblages rather than single fish species. Due to the reduced spatial extension of suitable fish habitat in the eastern Mediterranean (eutrophic spots in an otherwise oligotrophic environment), different species (mainly anchovy and sardine) and age classes co-occur close together, and school clusters generally consist of schools belong-

Table 1. Acoustic survey and surveyed area characteristics. No. of transects = number of transects in each sub-area; Type of transect $=$ type of transect used in each sub-area; Area $=$ size of sub-area $\left(\text { in square nautical miles, } \mathrm{nm}^{2}\right)_{;}$Depth $=$mean bottom depth$_{;} \mathrm{EI}=$ enclosure index of each sub-area; $\mathrm{CV}=$ coefficient of variation of depth

\begin{tabular}{|c|c|c|c|c|c|c|c|}
\hline & Survey time & $\begin{array}{l}\text { No. of } \\
\text { transects }\end{array}$ & $\begin{array}{l}\text { Type of } \\
\text { transect }\end{array}$ & $\begin{array}{l}\text { Area } \\
\left(\mathrm{nm}^{2}\right)\end{array}$ & $\begin{array}{l}\text { Depth } \\
\text { (m) }\end{array}$ & $\mathrm{CV}$ & EI \\
\hline North Aegean Sea & Jun 1995, Jun 1996 & & & & & & \\
\hline Thracian Sea & & 8 & Parallel & 1260 & 92 & 0.84 & 0.39 \\
\hline Strymonikos Gulf & & 9 & Zig-zagged & 1169 & 95 & 0.62 & 0.71 \\
\hline Thermaikos Gulf & & 13 & Parallel & 1963 & 114 & 0.70 & 0.83 \\
\hline Central Aegean & Jul 1998, Jun \& Dec 1999, Dec 2000 & & & & & & \\
\hline North Evoikos Gulf & & 16 & Zig-zagged & 766 & 111 & 0.89 & 0.98 \\
\hline South Evoikos Gulf & & 10 & Parallel & 677 & 100 & 0.64 & 0.84 \\
\hline Ionian Sea & Jul 1998, Jun 1999, Dec 1999, Jan 2001 & & & & & & \\
\hline Corinthiakos Gulf & & 10 & Zig-zagged & 781 & 391 & 0.71 & 0.97 \\
\hline Patraikos Gulf & & 7 & Zig-zagged & 337 & 74 & 0.32 & 0.80 \\
\hline Northern Ionian Sea & & 9 & Parallel & 1571 & 251 & 1.33 & 0.67 \\
\hline Southern Ionian Sea & & 9 & Parallel & 777 & 412 & 0.91 & 0.49 \\
\hline
\end{tabular}



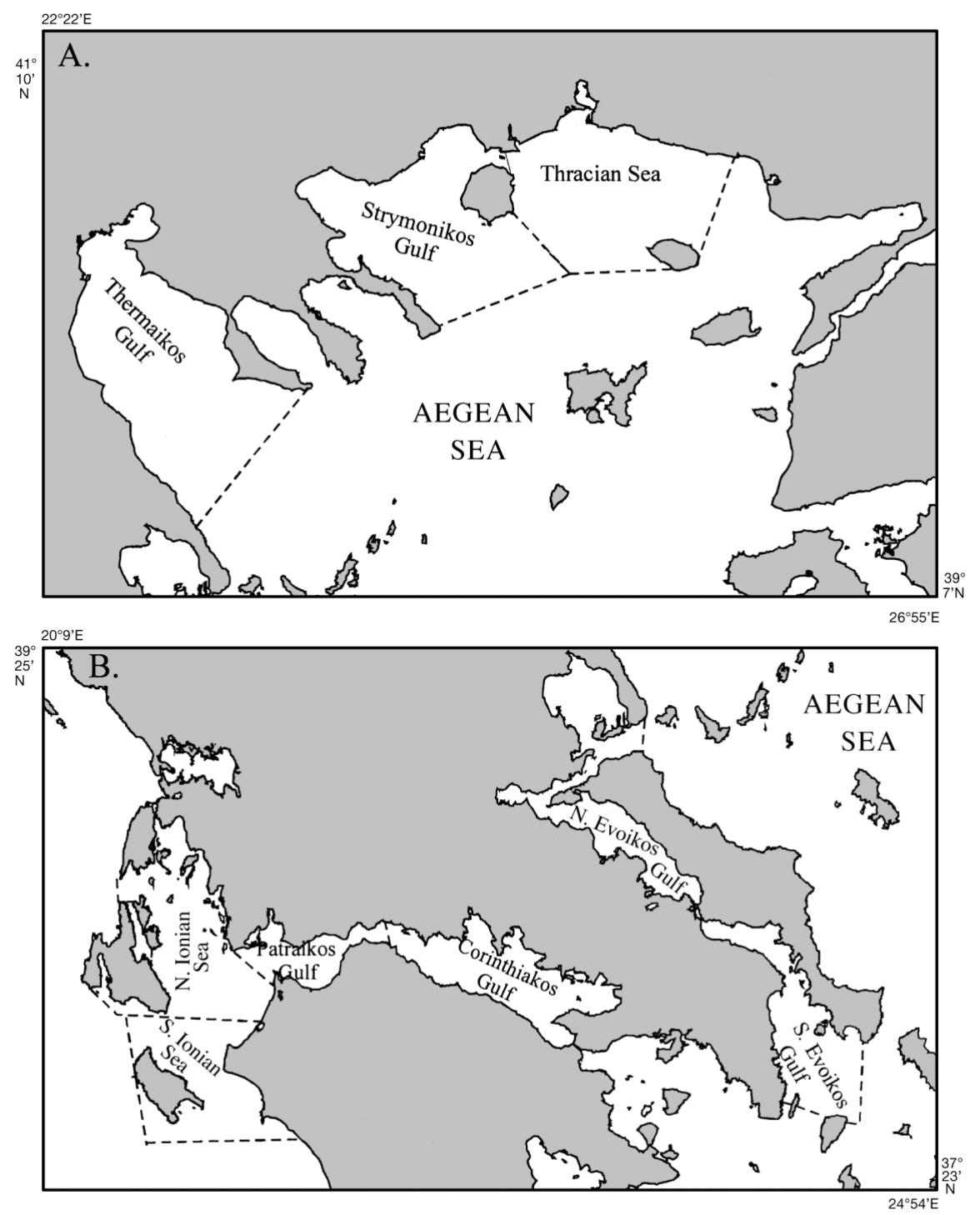

Fig. 1. Study area in the Aegean and Ionian Seas with the sub-area divisions. (a) North Aegean Sea; (b) central Aegean and Ionian Seas. Dashed lines define the boundaries of sub-areas. Toponyms mentioned in the text are shown

out to identify factors that might affect the spatial structure of echoes; (2) geostatistical analysis was then applied to investigate the structural fluctuations in echo spatial autocorrelation in order to determine patterns in fish distribution; and (3) the effect of the factors identified in the first step on calculated geostatistical parameters was examined by multiple regression analysis.

The exploratory data analysis included: (1) Target strength frequency histograms at $0.2 \mathrm{db}$ class intervals. Increased frequency of higher target strength values in an area might be indicative of dense fish aggregations occurring in that area. (2) The integrated back scattering cross section and corresponding difference in average bottom depth for each EDSU were plotted on the cruise track (sequential EDSU values) to examine depth-related changes in the echo distribution.

Subsequently, fish spatial distribution (i.e. fish echo dispersal over space) was used and geostatistical techniques were applied to analyze fish echo spatial autocorrelation, identify its structural component and thus visualize the 'intrinsic' spatial structure of pelagic fish assemblages in each sub-area (i.e. considering the spatial structure irrespectively of location).

The coordinates on the original surveys were expressed as degrees of longitude and latitude. To use the coordinates in the data analysis, lati-

ing to more than 1 species/length class, probably with a high frequency of mixed-species schools (Tsimenides et al. 1992, A. Machias unpubl. data, see also Bahri \& Freon 2000). Indeed, the catch of $79.6 \%$ of the identification hauls made during the surveys consisted of 2 or more species. The multispecies school clusters are exploited by the purse seine fleet (Stergiou et al. 1997).

Data analysis. The acoustic data analysis was performed separately in 9 sub-areas (Fig. 1, Table 1). The division in sub-areas was based on their geographic separation and/or differences in hydrographic and bathymetric characteristics (Ramfos et al. 2000, Somarakis et al. 2002).

In each sub-area, the overall analysis followed 3 major steps: (1) exploratory analysis was first carried tude degrees were converted to nautical miles and distances were calculated by multiplying the longitude and the cosine of the mean latitude in each sub-area (Petitgas 1993b). We applied variogram models to echoes samples (Armstrong et al. 1992, Barange \& Hampton 1997). Semi-variogram $(\gamma(h))$ is defined as the variance of the difference between values that are $h$ distance units apart and:

$$
2 \gamma(h)=\operatorname{var}[u(x)-u(x+h)]
$$

where $u(x)$ is the sum of acoustic cross-section/mile at location $x ; u(x+h)$ is the sum of acoustic crosssection/mile at distance $h(\mathrm{~nm})$ away from $x_{;} \operatorname{var}(u)$ is the variance; and $\gamma(h)$ is the semi-variogram. For simplicity we hereafter refer to $\gamma(h)$ as the variogram. 
Two basic assumptions of the variogram are the homogeneity of the population (e.g. absence of extreme values) and intrinsic stationarity. Intrinsic stationarity means that a constant mean exists and the variance of fish acoustic cross section is defined by the magnitude of distance $h$ (Isaaks \& Srivastava 1989, Goovaerts 1997). Variograms can be computed as either an average over all directions (omnidirectional variogram; in which case the lag measure is scalar), or specific to particular direction (directional variogram; where the lag measure is a vector) (Rossi et al. 1992). In the omnidirectional variograms, the calculated autocorrelation is the same regardless of the direction being considered. When the autocorrelation is a function of both distance and direction, the structure is anisotropic and should be looked at 1 direction at a time (Armstrong et al. 1992, Rossi et al. 1992). The peculiar features of the surveyed areas (e.g. mostly semiclosed, small-sized gulfs, presence of islands) implied different variogram behavior depending on direction; thus both omnidirectional and multi-directional variogram plots were computed in each sub-area (Isaaks \& Srivastava 1989, Rossi et al. 1992). The latter are mentioned as exhaustive variograms in Rossi et al. (1992).

Since acoustic data were highly skewed and some extremely high values were observed, values were truncated to a maximal value that represented the $98 \%$ level of a normal probability plot, and a natural logarithm (ln) transformation was applied to normalize the data. To avoid possible trends, we estimated a multiple regression model of $\ln ($ integrated echo) versus longitude, latitude and bottom depth. We then constructed a variogram using the residuals derived from the multiple regression models (Rendu 1979, Armstrong 1984, Armstrong et al. 1992, Lo et al. 2001). The 3 parameters of the omnidirectional variogram (range, sill, and nugget effect) were estimated. Range is the distance beyond which the observations are not correlated in practice, representing the maximum diameter of the fish patches or clusters (Reid 2000). The sill is the variance of the random field, the asymptotic value of $\gamma(h)$. The nugget effect measures the micromeasurement error and the white noise for distance $h$ close to 0 (Cressie \& Chan 1989, Rossi et al. 1992), representing in practice the variance between replicates.

The spherical model was chosen as the most appropriate to fit the omnidirectional variogram (Cressie 1991):

$$
\begin{aligned}
0, & h=0 \\
\gamma(h)=c_{\mathrm{o}}+c_{\mathrm{S}}\left\{(3 / 2)\left(\|h\| / a_{\mathrm{S}}\right)-(1 / 2)\left(\|h\| / a_{\mathrm{S}}\right)^{3}\right\} & 0<\|h\|<a_{\mathrm{S}} \\
C_{\mathrm{o}}+C_{\mathrm{S}}, & \|h\| \geq a_{\mathrm{S}}
\end{aligned}
$$

where $\gamma(h)$ is the semi-variogram $\gamma$ for distance $h$; $C_{\mathrm{O}}$ is the nugget effect; $c_{\mathrm{S}}$ is the practical sill (data variance $\left.-C_{0}\right) ; a_{\mathrm{s}}$ is the range; and $\|h\|$ is the lag distance. The spatial analysis packages S+ Spatial Stats (Kaluzny et al. 2000) and Variowin v2.21 software (Pannatier 1996) were used for calculating variograms.

Exhaustive variograms were computed as a contour plot of the directional variograms in 16 different directions, calculated with $22.5^{\circ}$ step and $\pm 22^{\circ}$ tolerance. The distances of each directional variogram were converted into an $x$ - $y$-axis system and the Basis Radial Function algorithm of Surfer v.7 (Golden Software) was used to create the graphs. This 2-dimensional graph of spatial continuity permitted a quick and comprehensive appraisal of the data's directional spatial dependence, showing the spatial structure as a function of distance with contours depicting the autocorrelation values. The resulting plot was symmetrical about its origin since the variogram value for $+h$ was equal to that for $-h$ (Isaaks \& Srivastava 1989, Rossi et al. 1992). This kind of contour plot detects anisotropy directions with respect to the variability of the data values in different directions (Isaaks \& Srivastava 1989, Rossi et al. 1992, Goovaerts 1997, Ecker \& Gelfand 1999), which was judged necessary for the areas studied.

Changes in the 'intrinsic' spatial structure due to the morphology of the area were examined by backward stepwise multiple regression analysis (Wonnacott \& Wonnacott 1981). The significance of the regression models was tested by ANOVA. Selection of the significant $(\alpha=0.05)$ variables was based on $F=4$. Whenever more than 1 variable entered the model, the simple regression model for each separate variable was also calculated.

Following the exploratory data analysis, the degree of enclosure for each sub-area, the mean bottom depth and bottom depth variation seemed to affect the spatial structure of fish aggregations. As independent variables, we therefore used: (1) the Enclosure Index (EI), which indicates the degree of enclosure of a basin (DeLeiva Moreno et al. 2000):

$$
\mathrm{EI}=S_{\mathrm{C}} / S_{\mathrm{n}}
$$

where $S_{\mathrm{c}}$ is the length of the area's coastline; and $S_{\mathrm{n}}$ is the length of the line that defines the boundaries of the examined area (Fig. 1). Measurements were taken at the same scale, and the degree of invagination of the coastline was assumed to be constant among sites. Large EI values indicate that the basins concerned are enclosed communicating with the open sea or another adjacent basin through a narrow passage; (2) the mean bottom depth $(B) ;(3)$ the coefficient of variation $(\mathrm{CV})$ of bottom depth (depth heterogeneity); (4) the total surface of the sub-area in $\mathrm{nm}^{2}(A)$; the surface area was taken into account considering that the degree of enclosure should be coupled with a measure of the sub-area size. 
We used as dependent variables: (1) the range $\left(a_{\mathrm{s}}\right)$; $(2)$ the nugget effect $\left(c_{\mathrm{op}}\right)$ resulting from the omnidirectional variograms expressed in a relative scale:

$$
C_{\mathrm{op}}=C_{\mathrm{o}} /\left(C_{\mathrm{O}}+C_{\mathrm{S}}\right)
$$

Anisotropy was not modelled but, for the exhaustive variograms, we used the following geometric descriptors measured by image analysis techniques as dependent variables: (3) the surface area enclosed by the $100 \%$ standardized data variance contour $\left(A_{100}\right)$; (4) the anisotropy ratio $(\lambda)$ defined as the ratio of the major versus minor axis of the best fitted ellipse surrounding the $100 \%$ variance contour of the variogram (Isaaks \& Srivastava 1989, Ecker \& Gelfand 1999); (5) the anisotropy direction (AD), defined as the tangent of the anisotropy angle $(\theta)$ of the major axis of the best fitted ellipse surrounding the $100 \%$ variance contour of the variogram. Angles were measured counterclockwise from east (Isaaks \& Srivastava 1989).

(6) The ratio $R=A_{60} / A_{100}$, i.e. the surface $\left(A_{60}\right)$ enclosed by $60 \%$ of the variance contour versus the surface area $A_{100}$. The ratio $R$ is an estimate of the rate of echo autocorrelation change. A low value of $R$ means that a small autocorrelation distance is needed to explain the $60 \%$ of the overall variance (heterogeneous spatial structure). A high value of $R$ indicates a progressive change in the integrated echo with distance (homogeneous spatial structure). The numerator of $R$ ( $A_{60}$ in the present study) was selected as the surface enclosed by the minimum contour, which incorporated the nugget effect (i.e. the non-spatial component of the variogram) in exhaustive variograms of all sub-areas.

\section{RESULTS}

Exploratory data analysis showed that the target strength frequency distributions differed among subareas and seasons (Fig. 2). Echo traces derive either from single fish or, more often, from aggregations of fish. Hence, increased frequency of high target strength values could be indicative of denser fish aggregations (MacLennan \& Simmonds 1992, Reid 2000). An increased frequency of high target strength values was observed in areas with a high degree of enclosure during summer (Fig. 2a-c). This pattern was less pronounced in wintertime, when high target strength values were generally frequent in all areas, making the geometry effect of the area less clear (Fig. 2d,e). The plots of the integrated echoes and corresponding difference in average bottom depth for each EDSU along the cruise track in each sub-area showed a similar pattern in both seasons (Fig. 3). Fish tended to concentrate in areas associated with rapidly changing bottom depth (sharp bottom slope).

The omnidirectional variogram model for the residuals of $\ln$ (integrated echo) exhibited autocorrelation ranges of 4 to $18 \mathrm{~nm}$ (Table 2, Fig. 4). The variograms of the southern Ionian Sea and Corinthiakos Gulf showed the slightest nugget effect in almost all cases. In general, the Thracian Sea and the Patraikos Gulf had variograms with strong nugget effect (less spatial structure) (Fig. 4, Table 2). In the exhaustive variograms (Fig. 5) anisotropy was apparent in almost all cases but was not consistent in direction or magnitude at any particular location (Table 2 ). The ratio $(R)$ of the surface $A_{60}$ to surface area $A_{100}$ of the exhaustive variograms (Table 2) ranged from 0.072 (North Evoikos Gulf in summer 1999) to 0.243 (Patraikos Gulf in winter 1999). For the majority of the areas, a slight increase in the $R$-values appeared in the winter period.

The stepwise multiple regression analysis (Table 3 ) showed that, from the dependent variables selected (i.e. $a_{\mathrm{s}}, c_{\mathrm{op}}, A_{100}, \lambda, \mathrm{AD}$, and $R$ ), only $c_{\mathrm{op}}$ and $R$ were related to certain potential independent variables. Specifically, in the $C_{\text {op }}$, models only mean bottom depth $(B)$ was selected $\left(c_{\mathrm{op}}\right.$ was decreasing towards greater mean bottom depths, Table 3), whereas in the $R$ models, both EI and $A$ were significant (Fig. 6). However, in the simple regression analysis (Table 3$) R$ was significantly related to EI in summer and $A$ in winter (Table 3). The logarithmic transformation of EI and $A$ improved the models in terms of variance explanation and residual characteristics (Table 3).

The multiple regression models predicted smallest value of $R$ in large enclosed basins (Fig. 6). $R$-values became larger with a decrease in $A$ and EI. The effect of the degree of enclosure was stronger in summer than in winter (Table 3), which opposed the effect of area size (stronger in winter than in summer).

\section{DISCUSSION}

In the present paper, we studied the link of topographic features to certain characteristics of the 'intrinsic' spatial structure of small pelagic fish populations using acoustic data from different areas with varying degree of land enclosure. In general, there is a lack of information on the effect of land on the spatial structure of small pelagic fish populations, as most such studies have been conducted in areas with rather simple topography (e.g. North Sea: Petitgas 1993b, Maravelias et al. 1996; Senegalese waters: Petitgas \& Lévénez 1996; the southern Benguela upwelling region: Barange \& Hampton 1997; the Bay of Biscay: Petitgas 1997; the south coast of western Australia: Fletcher \& Summer 1999). 


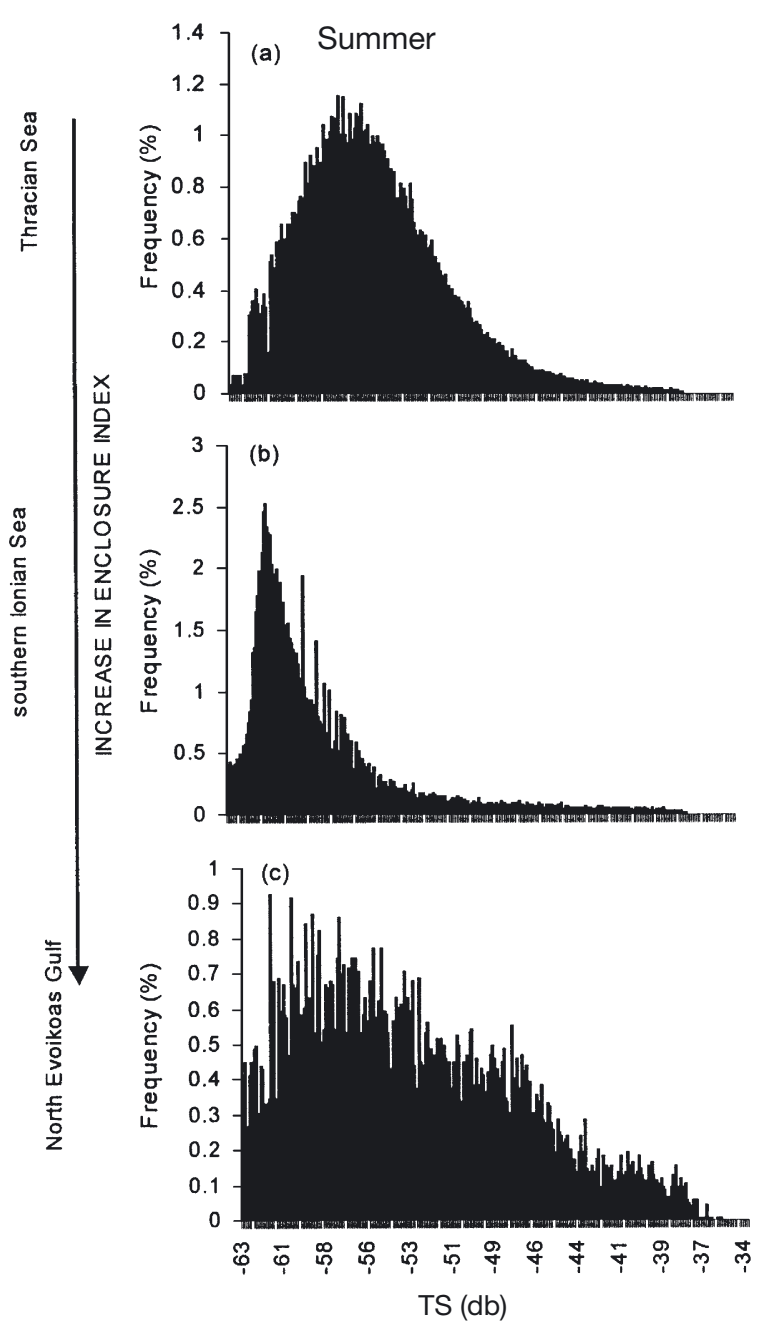

Winter

Fig. 2. Target strength (TS) frequency histograms in 3 characteristic sub-areas in summer and winter. Arrow indicates the gradient of enclosure index
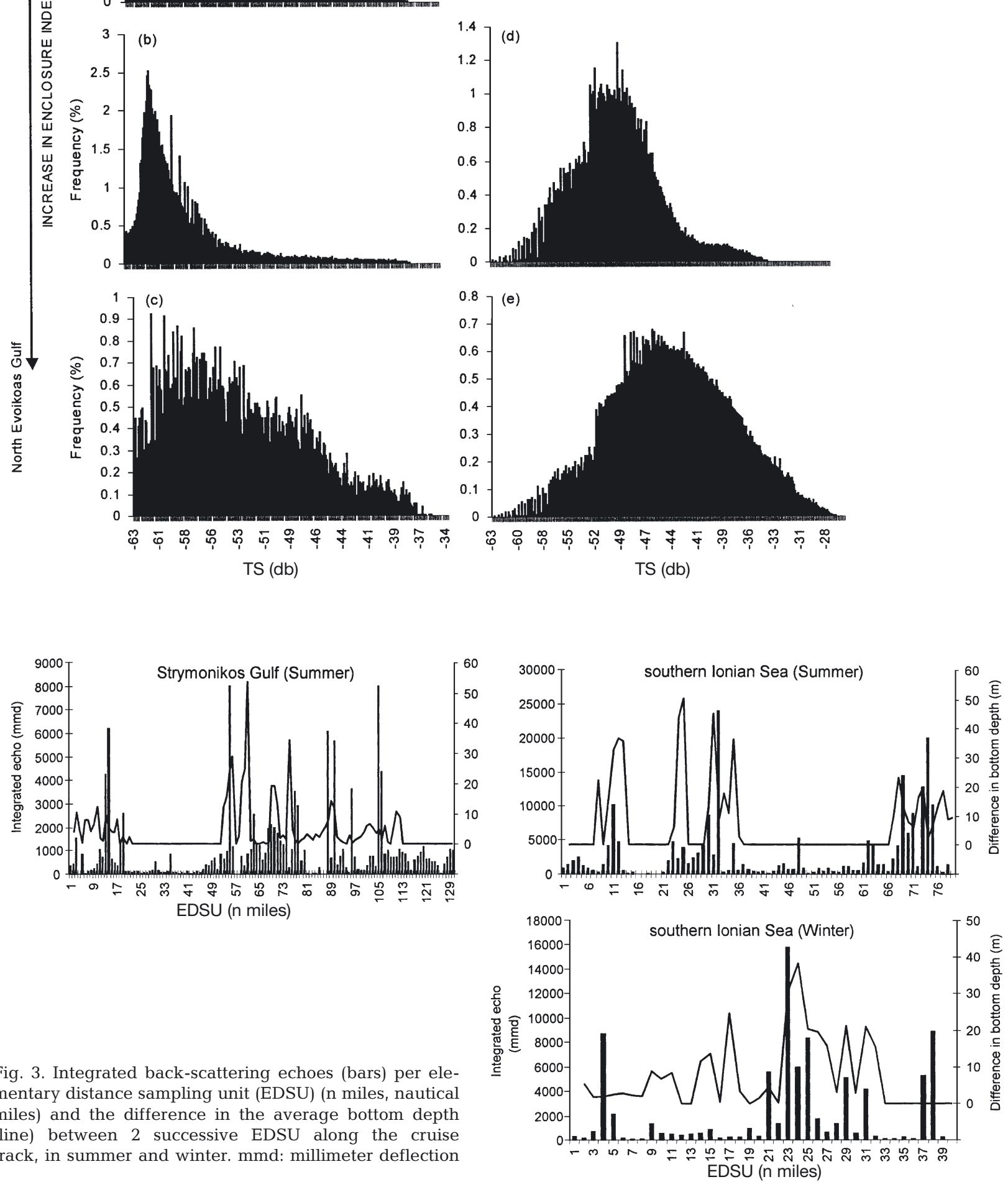

Fig. 3. Integrated back-scattering echoes (bars) per elementary distance sampling unit (EDSU) (n miles, nautical miles) and the difference in the average bottom depth (line) between 2 successive EDSU along the cruise track, in summer and winter. mmd: millimeter deflection 
Table 2. Parameters obtained by fitting spherical models to the omnidirectional variograms of the residuals: $a=$ autocorrelation range (in $\mathrm{nm}), C_{0} \%=$ nugget/data variance in percent; $C \%=$ sill/data variance in percent. Geometric descriptors of the exhaustive variograms: $R=$ ratio; $\lambda$ = anisotropy ratio; $\theta=$ anisotropy angle (in degrees)

\begin{tabular}{|c|c|c|c|c|c|c|c|}
\hline \multirow[t]{2}{*}{ Surveyed area } & \multirow[t]{2}{*}{$\begin{array}{l}\text { Sampling } \\
\text { period }\end{array}$} & \multicolumn{3}{|c|}{$\begin{array}{l}\text { Parameters of the } \\
\text { omnidirectional variograms }\end{array}$} & \multicolumn{3}{|c|}{$\begin{array}{l}\text { Geometric descriptors of the } \\
\text { exhaustive variograms }\end{array}$} \\
\hline & & $a$ & $C_{\mathrm{o}} \%$ & $C \%$ & $R$ & $\lambda$ & $\theta$ \\
\hline Thracian Sea & $\begin{array}{l}\text { Jun } 1995 \\
\text { Jun } 1996\end{array}$ & $\begin{array}{l}10 \\
14\end{array}$ & $\begin{array}{l}66.30 \\
50.60\end{array}$ & $\begin{array}{l}33.70 \\
49.40\end{array}$ & $\begin{array}{l}0.225 \\
0.182\end{array}$ & $\begin{array}{l}1.53 \\
1.11\end{array}$ & $\begin{array}{r}170.46 \\
56.53\end{array}$ \\
\hline Strymonikos Gulf & $\begin{array}{l}\text { Jun } 1995 \\
\text { Jun } 1996\end{array}$ & $\begin{array}{l}15 \\
11\end{array}$ & $\begin{array}{l}47.50 \\
49.30\end{array}$ & $\begin{array}{l}52.50 \\
50.70\end{array}$ & $\begin{array}{l}0.075 \\
0.096\end{array}$ & $\begin{array}{l}1.13 \\
1.23\end{array}$ & $\begin{array}{l}101.08 \\
119.36\end{array}$ \\
\hline Thermaikos Gulf & $\begin{array}{l}\text { Jun } 1995 \\
\text { Jun } 1996\end{array}$ & $\begin{array}{l}12 \\
10\end{array}$ & $\begin{array}{l}59.00 \\
42.00\end{array}$ & $\begin{array}{l}41.00 \\
58.00\end{array}$ & $\begin{array}{l}0.087 \\
0.074\end{array}$ & $\begin{array}{l}1.43 \\
1.10\end{array}$ & $\begin{array}{l}31.03 \\
57.08\end{array}$ \\
\hline North Evoikos Gulf & $\begin{array}{l}\text { Jul } 1998 \\
\text { Jun } 1999 \\
\text { Dec } 1999 \\
\text { Dec } 2000\end{array}$ & $\begin{array}{r}14 \\
5 \\
11 \\
4\end{array}$ & $\begin{array}{l}60.56 \\
29.30 \\
40.80 \\
64.20\end{array}$ & $\begin{array}{l}39.44 \\
70.70 \\
59.20 \\
35.80\end{array}$ & $\begin{array}{l}0.088 \\
0.073 \\
0.120 \\
0.084\end{array}$ & $\begin{array}{l}1.31 \\
1.33 \\
1.06 \\
1.02\end{array}$ & $\begin{array}{r}39.65 \\
122.39 \\
30.43 \\
16.72\end{array}$ \\
\hline South Evoikos Gulf & $\begin{array}{l}\text { Jul } 1998 \\
\text { Jun } 1999 \\
\text { Dec } 1999 \\
\text { Dec } 2000\end{array}$ & $\begin{array}{l}13 \\
12 \\
18 \\
10\end{array}$ & $\begin{array}{l}34.50 \\
57.00 \\
29.77 \\
50.95\end{array}$ & $\begin{array}{l}65.50 \\
43.00 \\
70.23 \\
49.05\end{array}$ & $\begin{array}{l}0.084 \\
0.096 \\
0.136 \\
0.128\end{array}$ & $\begin{array}{l}1.20 \\
1.11 \\
1.28 \\
1.27\end{array}$ & $\begin{array}{r}146.61 \\
8.81 \\
98.86 \\
70.48\end{array}$ \\
\hline Corinthiakos Gulf & $\begin{array}{l}\text { Jul } 1998 \\
\text { Jun } 1999 \\
\text { Dec } 1999 \\
\text { Jan } 2001\end{array}$ & $\begin{array}{r}13 \\
17 \\
8 \\
10\end{array}$ & $\begin{array}{l}49.18 \\
35.00 \\
23.50 \\
29.60\end{array}$ & $\begin{array}{l}50.82 \\
65.00 \\
76.50 \\
70.40\end{array}$ & $\begin{array}{l}0.122 \\
0.136 \\
0.083 \\
0.137\end{array}$ & $\begin{array}{l}1.50 \\
1.25 \\
1.37 \\
1.11\end{array}$ & $\begin{array}{r}167.91 \\
170.85 \\
118.15 \\
84.81\end{array}$ \\
\hline Patraikos Gulf & $\begin{array}{l}\text { Jul } 1998 \\
\text { Jun } 1999 \\
\text { Dec } 1999 \\
\text { Jan } 2001\end{array}$ & $\begin{array}{r}4 \\
11 \\
7 \\
10\end{array}$ & $\begin{array}{l}54.80 \\
37.00 \\
60.00 \\
57.00\end{array}$ & $\begin{array}{l}45.20 \\
63.00 \\
40.00 \\
43.00\end{array}$ & $\begin{array}{l}0.184 \\
0.194 \\
0.243 \\
0.205\end{array}$ & $\begin{array}{l}1.51 \\
1.46 \\
1.58 \\
1.23\end{array}$ & $\begin{array}{r}8.73 \\
170.92 \\
79.48 \\
126.09\end{array}$ \\
\hline Northern Ionian Sea & $\begin{array}{l}\text { Jul } 1998 \\
\text { Jun } 1999 \\
\text { Dec } 1999 \\
\text { Jan } 2001\end{array}$ & $\begin{array}{r}8 \\
16 \\
5 \\
13\end{array}$ & $\begin{array}{l}41.77 \\
56.01 \\
37.22 \\
33.50\end{array}$ & $\begin{array}{l}58.23 \\
43.99 \\
62.78 \\
66.50\end{array}$ & $\begin{array}{l}0.175 \\
0.106 \\
0.081 \\
0.095\end{array}$ & $\begin{array}{l}1.30 \\
1.68 \\
1.06 \\
1.23\end{array}$ & $\begin{array}{r}14.92 \\
56.93 \\
77.81 \\
102.72\end{array}$ \\
\hline Southern Ionian Sea & $\begin{array}{l}\text { Jul } 1998 \\
\text { Jun } 1999 \\
\text { Dec } 1999 \\
\text { Jan } 2001\end{array}$ & $\begin{array}{r}12 \\
8 \\
15 \\
10\end{array}$ & $\begin{array}{l}28.28 \\
25.60 \\
21.25 \\
42.82\end{array}$ & $\begin{array}{l}71.72 \\
74.40 \\
78.75 \\
57.18\end{array}$ & $\begin{array}{l}0.179 \\
0.147 \\
0.132 \\
0.212\end{array}$ & $\begin{array}{l}1.03 \\
1.09 \\
1.24 \\
1.19\end{array}$ & $\begin{array}{r}86.28 \\
33.09 \\
121.25 \\
101.25\end{array}$ \\
\hline
\end{tabular}

In an initial exploratory step of the study, we used the raw acoustic data to seek out factors potentially affecting the pattern of echo distribution. We observed that the fish tended to associate with rapidly changing bottom depth (sharp bottom slope) in both summer and winter. Similarly, Mais (1977) reported the frequent association of northern anchovy Engraulis mordax with sudden breaks in the bottom depth. This behavior is probably related to the existence of increases in current velocity and turbulence there, which are favorable for production and predation (Freon \& Misund 1999). During summer, the frequency of the big target strength classes (denser fish aggregations) was higher in sub-areas with an increased degree of enclosure than in open sub-areas. This difference was less pronounced in wintertime, when big target strength classes were observed in all areas. The latter implied seasonal variability in small pelagic fish patches in relation to area topography. Seasonal variation could be related to species biology and/or environmental conditions. Following these observations, it was con- cluded that parameters related to bottom depth and area enclosure could affect the spatial patterns of fish aggregations.

Subsequently, geostatistical techniques were applied to yield information about the spatial continuity of data. Both omnidirectional and exhaustive variograms were calculated, and showed well-defined spatial patterns that varied with the sub-area studied.

The estimated autocorrelation range of omnidirectional variograms indicated that fish formed mesoscale to large-scale patches (Maravelias \& Haralabous 1995). The autocorrelation range was not significantly related to any of the area characteristics examined, whereas the nugget effect was negatively correlated to mean bottom depth. Pelagic fish formed less structured aggregations (stronger nugget effect) towards shallower areas in both seasons. Barange \& Hampton (1997) suggested that a stronger nugget effect is likely to be caused by the greater patchiness of the population and lack of pattern in space allocation of these patches. Similarly, Guillard \& Lebourges (1998) ob- 

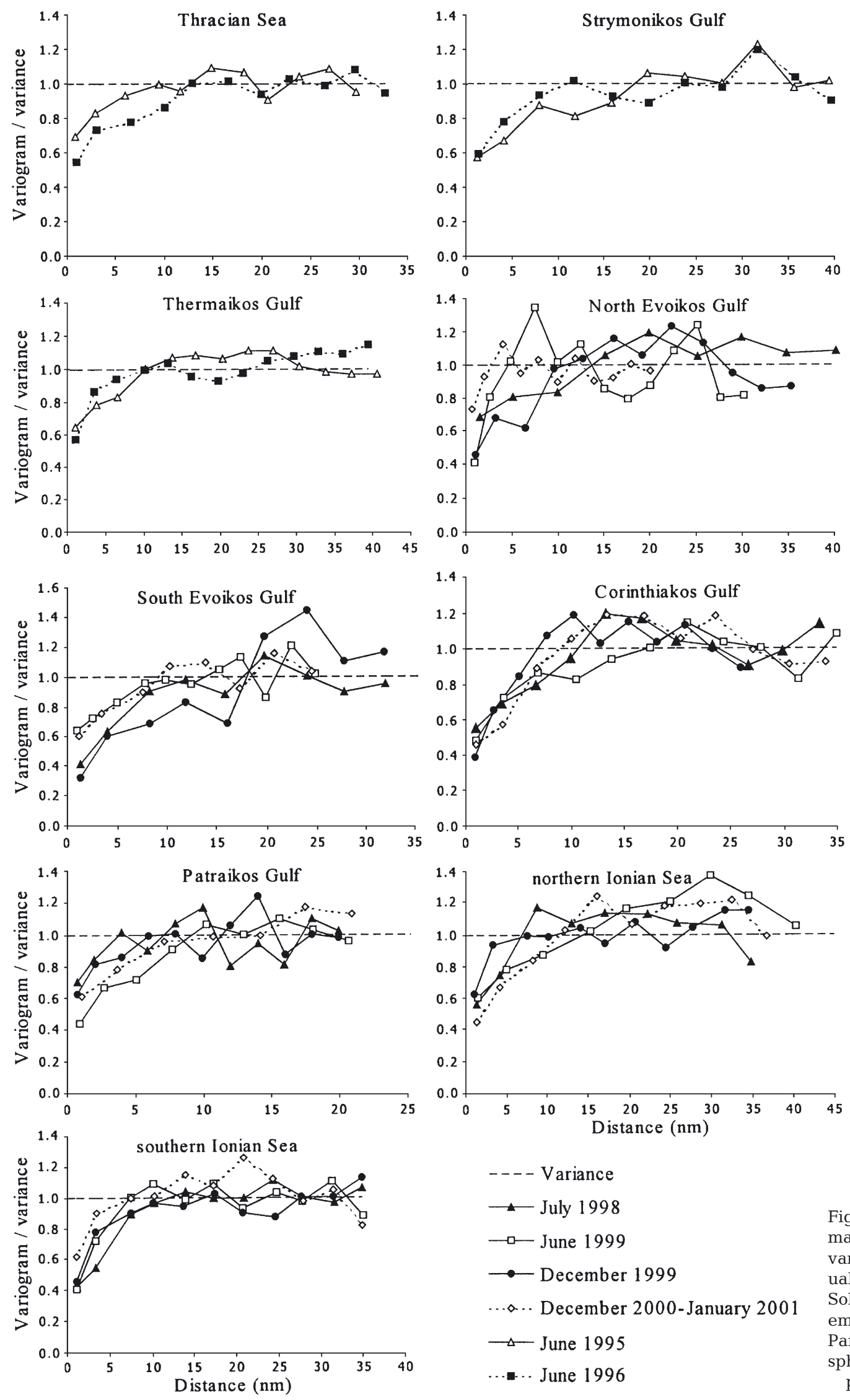

-.-- Variance

« July 1998

$\longrightarrow$ - June 1999

$\longrightarrow$ December 1999

…. December 2000-January 2001

$\triangle-$ June 1995

...... June 1996
Fig. 4. Experimental normalized omnidirectional variograms of the residual ln (integrated echo). Solid symbols: summer; empty symbols: winter. Parameters of the fitted spherical models are presented in Table 2 

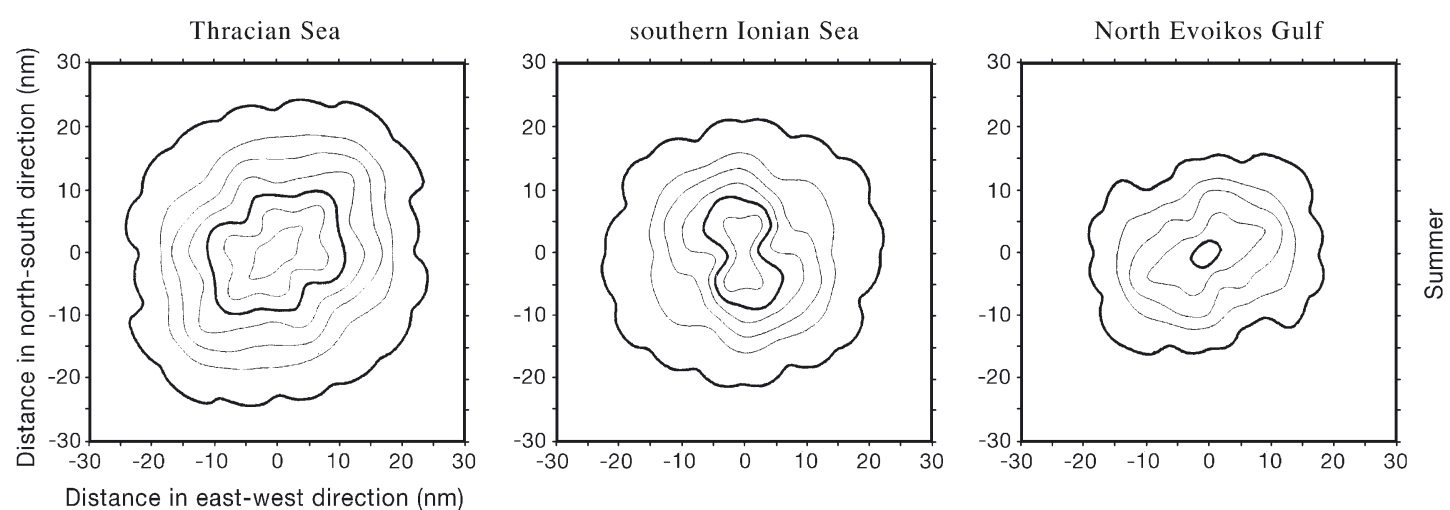

Fig. 5. Exhaustive variograms for 3 characteristic sub-areas with different degrees of enclosure in summer and winter. Sills are normalized by the data variance to facilitate comparisons; in addition, variogram values greater than the sill value were omitted in order to facilitate visual observation. Upper panels refer to the summer period, lower panels the winter period. Bold contour lines correspond to $60 \%$ (inner line) and $100 \%$ (outer line) of the data variance
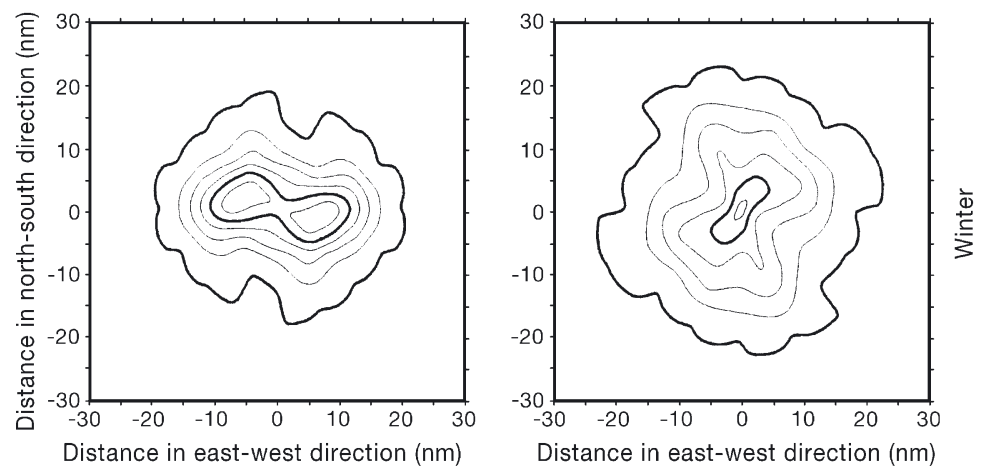

Increased Enclosure Index

served either complete absence of spatial structure (pure nugget effect) or high loss of structure (strong nugget effect) for pelagic fish populations in shallow waters. The relation of nugget to mean bottom depth, as opposed to autocorrelation range, suggested that area bathymetry affected the degree to which a spatial structure exists but not its maximum size.

Exhaustive variograms, although not commonly used in practice, provide an effective summary of spatial continuity and permit a quick and comprehensive appraisal of the directional spatial dependence of data (Isaaks \& Srivastava 1989, Rossi et al. 1992, Ecker
\& Gelfand 1999). Parameters calculated from the exhaustive variograms provided a most efficient picture of the underlying spatial continuity, especially in highly heterogeneous environments such as the studied areas.

In the multiple regression analysis, the $A_{100}$, as well as the anisotropy-related parameters $\lambda$ and $\mathrm{AD}$ of the exhaustive variograms were not significantly related to any of the variables examined. In contrast, the ratio $R$ was significantly affected by some of these variables, i.e. EI and $A$. The higher percentage of the variance was explained by EI in summer and $A$ in winter (simple regression analysis). $R$ expresses the rate of change

Table 3. Stepwise multiple regression models. Whenever more than 1 independent variable entered the model, the simple regression models for each variable are also shown. $C_{\mathrm{op}}=$ the nugget effect; $R=$ ratio; $A=\ln$ of area size in $\mathrm{nm}^{2} ; I=\ln _{\text {of }}$ enclosure index; $D=$ bottom depth in $\mathrm{m}_{i} \mathrm{r}^{2}=$ the adjusted coefficient of determination; $F=$ value of $F$-test; $\mathrm{p}$-value = probability value

\begin{tabular}{|c|c|c|c|c|}
\hline Period & Regression model & $\mathrm{r}^{2}$ & $F$ & $\mathrm{p}$-value \\
\hline Summer & $C_{\mathrm{op}}=0.5396-0.0005 \times D$ & 0.186 & 4.88 & 0.042 \\
\hline Winter & $C_{\mathrm{op}}=0.5692-0.0007 \times D$ & 0.469 & 10.70 & 0.008 \\
\hline Summer & $\begin{aligned} & R=0.4053-0.1233 \times I-0.0465 \times A \\
& \text { Simple regression: } R=-0.1040 \times I+0.0943 \\
& R \text { on } A \text { not significant relationship }\end{aligned}$ & $\begin{array}{l}0.572 \\
0.369\end{array}$ & $\begin{array}{l}12.35 \\
10.92\end{array}$ & $\begin{array}{l}0.001 \\
0.005\end{array}$ \\
\hline Winter & $\begin{array}{l}R=0.7730-0.1034 \times I-0.1001 \times A \\
\text { Simple regression: } R \text { on } I \text { not significant relationship } \\
R=-0.0882 \times A+0.7209\end{array}$ & 0.738 & 16.55 & 0.001 \\
\hline
\end{tabular}



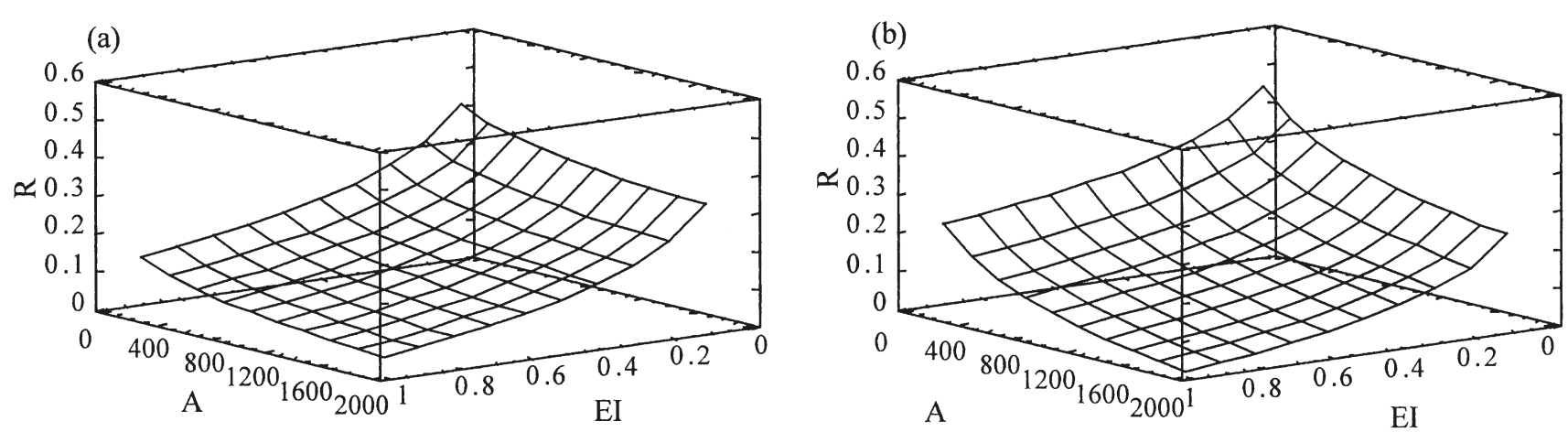

Fig. 6. Diagrammatic presentation of multiple regression models. (a) Summer; (b) winter. $R=$ ratio of the surface $A_{60}$ to surface area $A_{100}$ in the contour plot; $A=$ size of area $\left(\right.$ in $\left.\mathrm{nm}^{2}\right)$; EI $=$ enclosure index

in the echo autocorrelation, i.e. whether the echo variance changes progressively with distance (high $R$-values), or sharp changes in echo variance exist (lower $R$-values), the latter being indicative of higher structure heterogeneity. Thus, $R$ can be considered to reflect the internal organization of the spatial structure of fish populations (i.e. the schools' distribution within a cluster of schools). The autocorrelation range of omnidirectional variograms is rather indicative of the maximum diameter of fish patches or clusters of schools (Reid 2000). The relation of $R$ to certain topographic features of the studied sub-areas, as opposed to autocorrelation range, suggested that the geometry of the area affected the organization of the spatial structure (i.e. the way clusters of schools are organized) but not its maximum size.

It is known that, within a cluster of schools, the distribution in space can be very heterogeneous with several nuclei or cores (Freon \& Misund 1999). In the present study, lower $R$-values were calculated for closed than for open sub-areas during both seasons (Fig. 6). In general, heterogeneity is amplified when local topography increases the environmental patchiness (Freon \& Misund 1999). The closed sub-areas show high heterogeneity due to the coastline effects, namely the higher extension of coastal bathymetric ranges and terrestrial influence. The extended coastline increases localities of exogenous nutrient enrichment and enhances spatial variation in the wind mixing effect and water column stratification. In addition, in closed sub-areas, geometry affects the way fish are distributed near the border limits (sensu Beverton \& Holt 1957). The latter amplifies heterogeneity of the spatial structure of fish populations.

In the range of values used in the present study and for a given degree of enclosure, the spatial structure of fish populations was more homogeneous (greater $R$ values) in small-sized sub-areas than in large subareas. This could be explainable in terms of the total available area of the favorable fish habitat. In large seas, favorable habitats, which are generally localized systems (e.g. fronts), might be sufficiently large to carry most of the fish abundance. In small-sized gulfs such systems would be small, carrying less fish; hence, schools might eventually wander away (sensu Bakun 2001) in search for other favorable spots.

In conclusion, environmental spatial heterogeneity seems to affect the spatial structures of the small pelagic fish assemblages. The spatial structure of fish populations was more heterogeneous in closed subareas and, for a given degree of enclosure, in larger sub-areas. Parameters related to the internal organization of the spatial structure of fish populations (i.e. nugget and $R$ ) seemed to be related to the area topography in a consistent manner, while parameters related to the maximum size of the spatial structure and the way it changes with direction (range, $\lambda, \theta$ ), were not. This variability in aggregation patterns might have implications for both commercial fishing activity and for assessment surveys, as probability of encounter depends on aggregation.

The spatial organization of small pelagic fish populations cannot be solely explained by area geometry. It is most likely the result of a number of parameters that potentially interact, such as density dependence, seasonal variation in species and length compositions, along with area topography (Freon \& Misund 1999). In order to address these issues, a single species approach (i.e. echo partitioning into species) is further needed to examine the combined effect of area topography and density dependence on the spatial structure of different species populations. The present study did not account for the effect of other parameters; however, it succeeded in showing an overall effect of coastal topography on the spatial structure of pelagic fish populations.

Acknowledgements. This study was partially financed by the Commission of the European Union (Contract Numbers 97/048 and 98/039). 


\section{LITERATURE CITED}

Armstrong M (1984) Common problems seen in variograms. Math Geol 16(3):305-313

Armstrong M, Renard D, Rivoirard J, Petitgas P (1992) Geostatistics for fish survey data. Centre de Geostatistique, Fontainebleau

Bahri T, Freon P (2000) Spatial structure of coastal pelagic schools descriptors in the Mediterranean Sea. Fish Res 48: 157-166

Bakun A (2001) 'School-mix feedback': a different way to think about low frequency variability in large mobile fish populations. Prog Oceanogr 49:485-511

Bakun A, Cury P (1999) The 'school trap': a mechanism promoting large amplitude out-of-phase population oscillations of small pelagic fish species. Ecol Lett 2:349-351

Barange M, Hampton I (1997) Spatial structure of co-occurring anchovy and sardine populations from acoustic data: implications for survey design. Fish Oceanogr 6(2):94-108

Bazigos G (1974) The design of fisheries statistical surveysinland waters. FAO Fish Tech Pap 133

Beverton RJH, Holt SJ (1957) On the dynamics of exploited fish populations. Ministry of Agriculture, Fisheries and Food, London

Bez N, Rivoirard J (2001) Transitive geostatistics to characterize spatial aggregations with diffuse limits: an application on mackerel ichthyoplankton. Fish Res 50:41-58

Biosonics (1992) Echo signal processor. Biosonics, Seattle

Cressie NAC (1991) Statistics for spatial data. John Wiley \& Sons, New York

Cressie NAC, Chan NH (1989) Spatial modeling of regional variables. J Am Stat Assoc 84(406):393-401

DeLeiva Moreno JI, Agostini VN, Caddy JF, Carocci F (2000) Is the pelagic-demersal ratio from fishery landings a useful proxy for nutrient availability? A preliminary data exploration for the semi-enclosed seas around Europe. ICES J Mar Sci 57:1091-1102

Ecker MD, Gelfand AE (1999) Bayesian modeling and inference for geometrically anisotropic spatial data. Math Geol 31(1):67-83

Fletcher WJ, Summer NR (1999) Spatial distribution of sardine (Sardinops sagax) eggs and larvae: an application of geostatistics and resampling to survey data. Can J Fish Aquat Sci 56:907-914

Foote KG (1987) Fish target strengths for use in echo integrator surveys. J Acoust Soc Am 82(3):981-987

Freon P, Misund OA (1999) Dynamics of pelagic fish distribution and behaviour: effects on fisheries and stock assessment. Fishing New Books, Oxford

Goovaerts P (1997) Geostatistics for natural resources evaluation. Oxford University Press, New York

Guillard J, Lebourges A (1998) Preliminary results of fish population distribution in a Senegalese coastal area with depths less than $15 \mathrm{~m}$, using acoustic methods. Aquat Living Resour 11:13-20

Isaaks EH, Srivastava RM (1989) Applied geostatistics. Oxford University Press, New York

Kaluzny S, Vega SC, Cardoso TP, Shelly AA (2000) S+ spatial stats. Springer, New York

Lo NC, Hunter JR, Charter R (2001) Use of a continuous egg sampler for ichthyoplankton surveys: application to the estimation of daily egg production of Pacific sardine (Sardinops sagax) off California. Fish Bull 99:554-571

MacLennan DN, Simmonds EJ (1992) Fisheries acoustics.
Chapman \& Hall, London

Mais KF (1977) Acoustic surveys of northern anchovies in a California current system. Rapp P-V Reun Cons Int Explor Mer 170:287-295

Maravelias CD, Haralabous J (1995) Spatial distribution of herring in the Orkney/Shetland area (northern North Sea): a geostatistical analysis. Neth J Sea Res 34(4):319-329

Maravelias CD, Reid DG, Simmonds EJ, Haralabous J (1996) Spatial analysis and mapping of acoustic survey data in the presence of high local variability: geostatistical application to the North Sea herring (Clupea harengus). Can J Fish Aquat Sci 53:1497-1505

Pannatier Y (1996) Variowin: software for spatial data analysis in 2d. Springer-Verlag, New York

Petitgas P (1993a) Geostatistics for fish stock assessments: a review and an acoustic application. ICES J Mar Sci 50: 285-298

Petitgas P (1993b) Use of a disjunctive kriging to model areas of high pelagic fish density in acoustic fisheries surveys. Aquat Living Resour 6:201-209

Petitgas P (1997) Sole egg distributions in space and time characterized by a geostatistical model and its estimation variance. ICES J Mar Sci 54:213-225

Petitgas P, Lévénez JJ (1996) Spatial organization of pelagic fish: echogram structure, spatio-temporal condition, and biomass in Senegalese waters. ICES J Mar Sci 53:147-153

Petitgas P, Reid D, Carrera P, Iglesias M, Georgarakos S, Liorzou B, Masse J (2001) On the relation between schools, clusters of schools, and abundance in pelagic fish stocks. ICES J Mar Sci 58:1150-1160

Ramfos A, Koutsikopoulos K, Fragopoulou N, Machias A, Somarakis S, Pyrovolaki E, Lykakis I (2000) Hydrology and biological features in the coastal areas of central Greece during the anchovy spawning period. Proc 6th Helminth Symp Oceanogr Fish, Chios, II:88-93

Reid DG (2000) Report on echo trace classification. ICES Coop Res Rep 238:107

Rendu JM (1979) Kriging, logarithmic kriging and conditional expectation, comparison of theory with actual results. Proc 16th Int Symp Applic Comput Operations Res Mineral Indust (APCOM), New York, p 199-212

Rossi RE, Mulla DJ, Journel AG, Franz EH (1992) Geostatistical tools for modeling and interpreting ecological spatial dependence. Ecol Monogr 62(2):277-314

Schneider D (1989) Identifying the spatial scale of densitydependent interaction of predators with schooling fish in the southern Labrador current. J Fish Biol 35(Suppl A): 109-115

Somarakis S, Drakopoulos P, Filippou V (2002) Distribution and abundance of larval fishes in the northern Aegean Sea-Eastern Mediterranean in relation to early summer oceanographic conditions. J Plankton Res 24(4):339-357

Stergiou KI, Christou ED, Georgopoulos D, Zenetos A, Souvermezoglou C (1997) The Hellenic Seas: physics, chemistry, biology and fisheries. Oceanogr Mar Biol Annu Rev 35:415-538

Swartzman G (1991) Fish school formation and maintenance: a random encounter model. Ecol Model 56:63-80

Tsimenides N, Bazigos G, Georgakarakos S, Kapantagakis A (1992) Distribution of acoustic pelagic fish populations in the northern Aegean Sea. Proc World Fish Congr, Athens, 5:33-42

Wonnacott TH, Wonnacott RJ (1981) Regression: a second course in statistics. John Wiley \& Sons, New York

Submitted: September 16, 2002; Accepted: October 11, 2003 Proofs received from author(s): December 12, 2003 